\title{
Markus Fjellström
}

\author{
Food Cultures in Sápmi: An interdisciplinary approach \\ to the study of the heterogeneous cultural landscape \\ of northern Fennoscandia AD 600-1900
}

Stockholm University 2020

100 pages

ISBN 978-91-7911-064-2

\section{Review by Marianne Skandfer}

Markus Fjellström has presented a substantial doctoral work in scientific archaeology, comprising six articles and an 8o-page synthesis. The papers were published between 2015 and 202I. For the first time on such a large and systematic scale, these papers and thesis bring together specialists in Sámi and scientific/laborative archaeology to address the early history of the Sámi. The papers are co-authored by Fjellström and various archaeologists in Sweden, Finland and Norway. Fjellström's thesis comprises seven main chapters written in plain academic English, which allows the results and the general subject to be easily accessible outside the Nordic countries. It includes two summaries, written in Swedish and Pite-Sámi, respectively.

The main objective of the thesis is 'to highlight the heterogeneous cultural landscape in Sápmi through the study of food' (Fjellström 2020:I), focusing on the period AD 600-1900. Overarching questions are: I) if cultural diversity is reflected in food practices, 2) how individual life histories and mobility contribute to understanding of life in Sápmi, 3) what role reindeer had in local diets, and 4) what impact mining activity had on the well-being of local populations (Fjellström 2020:3-4). Fjellström's specialist field is in isotope and element analysis. Stable carbon $\left({ }^{{ }^{3}} \mathrm{C}\right)$, nitrogen $\left({ }^{15} \mathrm{~N}\right)$ and sulphur $\left.{ }^{(34} \mathrm{S}\right)$ isotope analyses are performed on different collagen-containing materials from humans and animals, supported by stable isotope analysis of 
strontium and elemental analysis of lead. All methods are clearly presented in the synthesis. The results are held together with zooarchaeological analysis and radiocarbon dating, providing new insights into local lives in Sápmi.

While all the papers follow strict scientific specialist presentation protocols, the thesis provides information on the Sápmi socio-historical context and ethical considerations on a more introductory level. This variety of approaches, both in terms of themes and presentation forms, has made it challenging to structure a short review. I have chosen to follow the main questions raised by Fjellström.

\section{Cultural diversity}

Sámi archaeology explicitly concerns Sámi culture and history. However, our research contributions to the field (still) mostly deal with contact and interaction between Sámi and non-Sámi groups, the Sámi partner often I suspect typically unconsciously - being constituted as the Other. Fjellström's work addresses contacts on the local level, investigating cultural diversity within Sápmi, the land of the Sámi. It writes itself into Sámi archaeology, through the use of laboratory analyses of human and animal remains, to provide new knowledge on Sámi society over time. Perhaps more importantly, the work highlights local community articulations of specific historical contexts.

One of the major strengths of this body of work is its focus on the different ways stable isotope analysis can be used and combined with selected additional methods. Two of the papers focus specifically on diversity within local communities.

The paper 'Food and cultural traits in coastal northern Finnmark in the I4th-Igth centuries' (Fjellström et al. 20I9) considers human skeletal remains from two island cemeteries in northern Norway. It aims to establish a firmer time frame for the cemeteries and to provide insights into diet and mobility in what are assumed to be different Sámi local groups. It is hypothesized that, although based on the coast, Sámi and other local groups had a diverse economy and diet, varying according to cultural preferences. Stable ${ }^{{ }_{3}} \mathrm{C},{ }^{15} \mathrm{~N}$ and ${ }^{44} \mathrm{~S}$ isotopes from bone, teeth and nails from a total of $\mathrm{I}_{5} \mathrm{hu}-$ man individuals are compared to reference material comprising animal bone from a contemporary hunting station site. When compared with previously published analyses in the wider northern Scandinavian region, the results show an overall marine diet for all the individuals buried at Kirkegårdøya, Western Finnmark, and much more variation at Guollesuolo/Gullholmen in eastern Finnmark. The population buried at the former site seems to be much more stationary than that of the latter, and it is suggested that the 
individuals at Gullesuolo/Gullholmen belong to several different groups, in line with Gullesuolo/Gullholmen's position as a trading post.

'Food, mobility and health in an Arctic I7th-I 8th century mining population' (Fjellström et al. 202I), looks at burials related to the multi-cultural mining community Sillbåjåhka/Silbojokk, established in I635. The results of stable ${ }^{13} \mathrm{C},{ }^{15} \mathrm{~N}$ and ${ }^{34} \mathrm{~S}$ isotope analysis of collagen from 28 individuals, in addition to ${ }^{87} \mathrm{Sr} /{ }^{86} \mathrm{Sr}$ (strontium) isotope and lead $(\mathrm{Pb})$ element analysis from molars from I I individuals, are compared with a large body of local contemporary faunal material, soil samples, water samples and minerals from mining (slag and pewter lump). It was expected that cultural food preferences would be expressed as differences in diet markers. However, at this site, very little variation was found between individuals, even across different cultural backgrounds. The diet was generally varied, with a large portion of local freshwater fish, but it also included forest fowl, domesticates and some reindeer. Furthermore, the population seems to have been stationary.

\section{Life histories and mobility}

Human life histories and mobility combine to form an underlying assumption in the papers and thesis: it is expected that individual background culturally and historically - can be found as environment-related imprints in the bone chemistry. It seems likely that dietary diversity suggests also cultural diversity, but the results from Sápmi imply that perhaps more significant in the period chosen is the fact that dietary similarities were profound between individuals across different cultural backgrounds, with a generally high dependence on local fish and small-game resources, including forest birds. Although variation has been identified, for example at the Gullesuolo/Gullholmen and Rounala cemeteries, an interesting general result is that even in multicultural communities such as the mining community of Sillbåjåhka/Silbojokk, differences between buried individuals have been detected only to a very limited degree. Mobility during life has been documented for very few individuals.

In the paper 'Consideration of freshwater and multiple marine reservoir effects: dating of individuals with mixed diets from northern Sweden' (Dury et al. 2018), stable ${ }^{{ }^{3}} \mathrm{C},{ }^{15} \mathrm{~N}$ and ${ }^{34} \mathrm{~S}$ isotopes are analysed from ${ }^{9} 9$ of 23 individuals identified from the interior of the churchyard at Rounala, Torne Lappmark. This paper is primarily concerned with methodology. The values are compared with contemporary animal and fish species assumed to have been included in their diet, and with previously published regional zooarchaeological reference material. Marine reservoir effect is corrected for the radiocarbon dates according to identified diet markers. The first burials are 
suggested to have taken place prior to the establishment of the church, and the latter were given up after the abandonment of the church and churchyard according to written sources. Interesting in terms of life history and mobility, the analysis identifies a varied diet for the buried individuals; this included reindeer as well as Atlantic cod, Baltic seal and salmon. The mixture thus points to resources that were native to a very different landscape than that of the Rounala region. Both people and animal resources probably moved around in the large north Scandinavian region.

In 'Fishing at Vivallen - stable isotope analysis of a south Sami burial ground' (Fjellström, Eriksson \& Lidén 2020), prior diet analyses are reconsidered according to relative importance of different food sources at Vivallen, a South-Sámi burial ground and dwelling site situated by a medieval trade and pilgrimage route. New stable ${ }^{{ }_{3}} \mathrm{C},{ }^{15} \mathrm{~N}$ and ${ }^{34} \mathrm{~S}$ isotope values from human skeletal remains from the burial ground and animal bones from the settlement site are compared to values from other sites in Sápmi. These include several of Fjellström's own analyses. The aim is to identify the relative importance of food sources and mobility patterns for individuals, humans and animals alike. Also here, the results point to a very similar but varied diet among the human individuals, with freshwater fish as the most important food resource. Diets have only changed to a limited degree during the individuals' lifetime, and all except one were of local origin. On the other hand, sulphur (S) values in bones of domesticates and reindeer demonstrate that several were brought to Vivallen from elsewhere. This touches upon the third main theme: the role of reindeer.

\section{The role of reindeer}

The role of reindeer is central to the thesis. Fjellström points out how a notion of reindeer as an important Sámi food resource has been assumed in previous presentations of Sámi communities and economy.

The paper 'Animal offerings at the Sámi offering site of Unna Saiva Changing religious practices and human-animal relationships' (Salmi et al. 2015) aims to investigate spatial and temporal variation in Sámi offering practices. Zoo-archaeological determining, stable isotope analyses and new radiocarbon dates of the animal bones from Unna Sáiva offering site reveal that animal offerings here have a deeper history than previously thought. Sacrificed animals were selected according to species that varied over time. Reindeer were chosen based on their sex, age and body size. The sacrificed reindeer seem to belong to a local, foddered herd. This implies that early on in the history of domestication at least sacrificed reindeer had their natural diet pattern influenced by humans through foddering. 
'Approaching historic reindeer herding in northern Sweden by stable isotope analysis' (Fjellström et al. 2020), explores the role of reindeer in different historical contexts in Sápmi with the use of stable ${ }^{13} \mathrm{C},{ }^{15} \mathrm{~N}$ and ${ }^{34} \mathrm{~S}$ isotope analysis from a minimum of five individual animals from five archaeological sites and one contemporary sample material. The sites represent settlements, an offering site and a marketplace, spanning between the eleventh and twentieth centuries. With a focus on the annual cycle and diet of reindeer, it was expected that different local natural environments and various relations with humans resulted in different reindeer herd diets. A difference is found between the sites. Offering sites seem to represent bones from homogenous local reindeer populations that were winter foddered. It is suggested that at each site offerings were performed by single local Sámi groups. On the other hand, variation in reindeer diet is found within settlement and market sites. This suggests different origins for the individual reindeer, and that perhaps both wild and domesticated reindeer are represented. Stable isotope analysis seems to be well suited for identifying the different ways that humans handle reindeer, on both the herd and individual levels.

One of the general patterns established in Fjellström's thesis is that reindeer were of limited importance as a food resource, regardless of time and space. This is an interesting and important insight to bring into the large reindeer domestication discussion. As already pointed out in several of the papers, other more stationary local resources, fish in particular, are instead identified as key staples. It is demonstrated how strongly food cultures in pre- and early industrial societies are related to resources directly available in the different local landscapes.

In this respect, I wish to comment on the contrasting use of figures in the papers and thesis respectively. Where the papers lean on natural science and metrical data presented in tables and diagrams following the running text, the thesis includes illustrations of portrait-like drawings of animals and of Angelica achangelica - a staple food-plant in the traditional Sámi diet. These illustrations affected me in a surprising and thought-provoking way, presenting resources as social co-actors. In this way, the thesis hints at the recent 'animal turn' in humanities and social sciences. Based on the new results on animal mobility and diet achieved by Fjellström and his colleagues, I believe the topic of human - animal relations should be followed up in future work.

\section{Health impact of mining}

Despite being one of the main questions raised by Fjellström himself, the health impact of mining on local populations is not much addressed. In 
'Food, mobility and health in an Arctic I7th-I8th century mining population' (Fjellström et al. 202I) it is concluded that every member of the community at Sillbåjåhka/Silbojokk was severely exposed to pewter pollution during his/her lifetime. The results reveal further evidence of heavy postburial pollution from the soil due to mining activity. A final consideration is made in the paper regarding mining as a colonial action in Sápmi, and this can perhaps be seen as a stepping-stone for the discussion in Chapter 6 of the thesis. Here, Fjellström considers the ethics of Western intervention in Sápmi in general, focusing on reburial and repatriation. By incorporating this into the thesis, Fjellström wishes to bring to the fore the processes, results and problems of academic use of past human remains. It is concluded that Sámi themselves need to be given the authority to manage their cultural heritage.

The subject has wide relevance and implications, and examples are given of considerations related to research, indigenous history and culture, politics and public access. In all parts of Sápmi in the last 20 to 25 years, as well as in the rest of the Western-influenced/colonized world, racial biology and nationalism in archaeological research history, as well as repatriation and reburial, have been critically discussed. Unfortunately, Fjellström's references are almost exclusively to examples and discussions in Sweden, and thus miss out central contributions to a difficult but important international debate. Two of his examples of reburials are from the cemeteries at Rounala and Sillbåjåhka/Silbojokk, discussed in the papers. A discussion of his own ethical concerns relating to choice of methods and research material should therefore have been included. Some of the examples from Sápmi include stable isotope information that has not been referred to in other parts of the study. A compilation and critical evaluation and discussion of available stable isotope analysis results would be a welcome followup on this theme.

The use (and not) of Sámi place-names is another area that could be further developed. Possessing the authority to officially name places is acknowledged to have profound social and political implications. Place-names affect the reader, and constantly remind us of the geo-cultural setting of the archaeological record. In Fjellström's collected papers, only Swedish place-names are provided, whereas Sámi names are used alongside these in the thesis. I would have wanted to see some reflection on the reasoning behind using/omitting Sámi local names, and think, following Fjellström's line of thought on Sámi self-determination regarding culture heritage management, that Sámi place-names should have been used throughout both the papers and thesis. 


\section{Where and when is Sápmi?}

In my view, Fjellström's present work should be regarded as Sámi archaeology. Sámi archaeology, having gained recognition as a field of research since the I980s, spans a vast geographical area, now divided between four nation states. Furthermore, it covers several millennia, and includes all the major culture-historical subjects, from settlement history, burial practices and religion, via economy from foraging to reindeer herding and farming, to tool technology. In addition, culture heritage management and research ethics, with a specific international dimension concerning the protection of indigenous material and intangible culture, are particular areas of study. Considering the range within this broad field, we have been - and are - relatively few working within Sámi archaeology. I believe I am not alone in experiencing that we still have to spend valuable time, written space and effort to argue for the mere existence and relevance of the field itself, before we can let ourselves dive into specific research questions. The thesis's objective, 'to highlight the heterogeneous cultural landscape in Sápmi through the study of food' (Fjellström 2020:I), is in my opinion met through three valuable contributions to Sámi archaeology:

I. Culture-historically. Better defined timeframes and local contexts for several already or soon-to-be classic sites are established. Fjellström presents a broader culture-historical background in Chapter 2 of his thesis. A dynamic understanding of ethnicity as a strategic means in social interaction is outlined, although I miss references to Barth (I969) as the source for this theoretical fundament in Scandinavian archaeology. The dynamic ethnicity model should have been actively used in the following presentation and discussion of group interaction. Instead, different Sámi and other groups are presented as separate ethnic entities, and little is said about types of contact and interaction and change over time. Sámi and other groups are presented, but the length and level of detail varies considerably, from several pages to a few lines. For some reason Nordic groups are omitted. I would have wanted a more balanced presentation of the socio-cultural and historical/temporal context. I find it to be too general and simplified, especially alongside the local level chosen for the papers. Primary sources are mostly ethnographic literature from the first part of the twentieth century, more or less implicitly of relatively short time-depth. This background chapter risks presenting Sámi culture as static and with a timeless past. Changing socio-political and historical contexts have-as shown in the papers - created a mosaic of different and shifting conditions for meetings and interactions. I miss more references to recent, and critical, archaeological literature, including a stronger 
chronological framework for cultural diversity through the I300-year period in question (see e.g., Wallerström I995; Broadbent 20I0; Hansen and Olsen 20I3). The thesis/synthesis also only to a very limited degree includes discussions about the history of Sápmi outside Sweden.

2. Choosing cultural diversity in Sápmi and Sámi local lives as the starting point for analysis. This contributes to placing Sámi archaeology within the established natural science archaeology of Fennoscandia. Research questions other than identifying Sámi are in focus. Fjellström's co-authored papers provide novel ways to approach local Sápmi (and not necessarily Sámi) communities, of which several of the ones chosen for investigation were multi-cultural, and also include human - animal relationships.

3. Taking Sámi archaeology into scientific archaeology. By this, Fjellström brings a new direction into the broader and otherwise culture-historical and ethnographically oriented field. There is, indeed, a difference in the amount of research effort invested for different prehistoric and historical periods and phases, and most written sources informing us of Sámi communities from the Viking Age onwards resulted from orders and regulations imposed by kings, church and other national authorities, be it tax lists, legal documents or reports. No doubt, scientific archaeology has the potential to add important knowledge on early as well as relatively recent Sámi local history.

Fjellström's analyses investigate material from contexts representing several major structural changes in Sápmi: reindeer domestication, colonization, mining, Christianization, taxation, organized trade and the drawing of national borders. The overall results suggest that in these times of fundamental change in Sápmi, food culture relied on locally available resources, across time, space and cultural diversity. These findings and their implications deserve to be further developed. As a start, the results from the different papers should be explicitly compared and discussed.

\section{References}

Barth, F. I969. Introduction. In: Barth, F. (ed.), Ethnic Groups and Boundaries: The Social Organization of Culture Difference, pp. 9-30. Oslo: Universitetsforlaget.

Broadbent, N. 2010. Lapps and labyrinths: Saami Prehistory, Colonization and Cultural Resilience. Washington, DC: Smithsonian Institution Scholarly Press. 
Dury, J.P.R., Eriksson, G., Fjellström, M., Wallerström, T. \& Lidén, K. 20ı8. Consideration of Freshwater and Multiple Marine Reservoir Effects: Dating of Individuals with Mixed Diets from Northern Sweden. Radiocarbon 60(5) pp. I56I-I585.

Fjellström, M. 2020. Food Cultures in Sápmi: An Interdisciplinary Approach to the Study of the Heterogeneous Cultural Landscape of Northern Fennoscandia AD 600-I90o. Department of Archaeology and Classical Studies, Stockholm University.

Fjellström, M., Eriksson, G., Lidén, K. \& Svestad, A. 2019. Food and Cultural Traits in Coastal Northern Finnmark in the I4th-I9th Centuries. Norwegian Archaeological Review 52 (I) pp. 20-40.

Fjellström, M., Eriksson, G., Angerbjörn, A. \& Lidén, K. 2020. Approaching Historic Reindeer Herding in Northern Sweden by Stable Isotope Analysis. Journal of Nordic Archaeological Science I9 pp. 63-75.

Fjellström, M., Eriksson, G. \& Lidén, K. 2020. Fishing at Vivallen: Stable Isotope Analysis of a South Sámi Burial Ground. Manuscript (preprint) URN: urn:nbn:se:su:diva-I79989

Fjellström, M., Lindgren, Å., López-Costas, O., Eriksson, G. \& Lidén, K. 202I. Food, Mobility and Health in an Arctic I7th-I8th Century Mining Population. Arctic 74(2) pp. 206-226.

Hansen, L.I. \& Olsen, B. 20I3. Hunters in Transition: An Outline of Early Sámi History. Leiden: Brill.

Salmi, A.K., Äikäs, T., Fjellström, M. \& Spangen, M. 20I5. Animal Offerings at the Sámi Offering Site of Unna Saiva: Changing Religious Practices and Human-Animal Relationships. Journal of Anthropological Archaeology 40 pp. 10-22.

Wallerström, T. I995. Norrbotten, Sverige och medeltiden: Problem kring makt och bosättning i en ruropeisk periferi. Stockholm: Almqvist \& Wiksell. 